\title{
Determinants of Adoption of Improved Teff Varieties by Smallholder Farmers: The Case of Kobo District, North Wollo Zone, Amhara Region, Ethiopia
}

\author{
Susie Teshome ${ }^{1, *}$, Bosena Tegegne ${ }^{2}$ \\ ${ }^{1}$ Department of Agricultural Economics, Woldia University, Woldia, Ethiopia \\ ${ }^{2}$ Departement of Agricultural Economics, Bahir Dar University, Bahir Dar, Ethiopia \\ Email address: \\ susrvp@gmail.com (S. Teshome), bosenat@gmail.com (B. Tegegne) \\ ${ }^{*}$ Corresponding author
}

To cite this article:

Susie Teshome, Bosena Tegegne. Determinants of Adoption of Improved Teff Varieties by Smallholder Farmers: The Case of Kobo District, North Wollo Zone, Amhara Region, Ethiopia. International Journal of Agricultural Economics. Vol. 5, No. 4, 2020 , pp. $114-122$. doi: $10.11648 /$ j.ijae.20200504.14

Received: May 29, 2020; Accepted: June 15, 2020; Published: July 28, 2020

\begin{abstract}
Adoption and wider diffusion of improved teff varieties is playing vital role in reversing the present situation of food insecurity in many parts of Ethiopia. However, the uses of improved teff varieties are constrained by various factors. Hence, in this study, an attempt was made to examine factors affecting adoption and intensity of use of improved teff varieties. A multi-stage random sampling technique was employed to select 150 sample households from Kobo district. Double-hurdle model was used to identify factors influencing households' adoption decision and intensity of use of improved teff varieties. The result of double-hurdle model shows that educational level of household head, participation on crop production demonstration, distance from the nearest market, frequency of extension contact, off/non-farm income, proportion of cultivated land allocated for teff, livestock holding, improved teff seed availability, and perception on better yielding capacity of the new varieties over local varieties were found to be significantly influencing households adoption decision, whereas, sex, age, family labor, membership to an organization, off/non-farm income, frequency of extension contact and land allocated for teff were found to be significantly influencing the intensity of use of improved teff varieties. Therefore, the result implies that strengthening the existing extension services, providing good transport facilities for farmers through infrastructural development, improving access to improved seeds, improving farmers' level of education, strengthening farmer's organization, encouraging the use of labour saving technologies, improving crop-livestock production system and provision of demonstrations of new technologies are areas that need policy attentions to enhance adoption and intensity of use of improved teff varieties. Further, high yielding teff varieties need to be given special priority in teff variety scaling out programs.
\end{abstract}

Keywords: Adoption, Improved teff Varieties, Double-hurdle Model, Intensity, Kobo

\section{Introduction}

Ethiopia is fundamentally an agrarian country and agriculture is Ethiopia's most important sector, crucial for the country's food security and the livelihoods of its people. The sector is the largest contributor to the overall economy and is fundamental to Ethiopia's overall development. Despite the dominance of traditional smallholder farmers in the sector, increased engagement with mid and large-scale private sector partners has brought new technologies and improved market linkages [2]. Although the transformation towards a more manufacturing and industrially oriented economy is well underway, the agriculture sector continues to be the most dominant aspect of the Ethiopian economy, accounting for nearly $42 \%$ of GDP, $85 \%$ of employment, and $90 \%$ of foreign export earnings [11].

Despite of its contribution to the national GDP by large, agriculture in Ethiopia is subsistence. Smallholder farmers are cultivating $95 \%$ of their farmland using mostly traditional farming practices and inadequate improved technology be found in the low productivity Ethiopian agriculture. Furthermore, the majority of the agriculture sector is made up 
of smallholder farmers who live on less than 1.17 hectares of land (38). This is particularly true to the major food crops grown in the country.

Teff is one of the cereals grown in most agro-ecological zones of Ethiopia and mainly used for food consumption. It ranks first in area coverage and second after maize in total production. The crop accounted for about $24.17 \%$ of the total grain cultivated land [11]. It is a multipurpose crop, being utilized in different forms where the grain is used to make the Ethiopian staple food, Injera. It is also valued for its fine straw, which is used for animal feed as well as for reinforcing mud for plastering wooden walls of buildings [6].

The popularity of teff can be also explained with its high price. It is the highest priced cereal grown in Ethiopia and is an attractive cash crop for farmers. Combined with the high share of the final price obtained by the farmers, income from teff is much higher than income from other cereals and even $34 \%$ higher than income from coffee, the major export crop in Ethiopia [25, 37]. About 25-30 million people are directly depend on teff production. The higher teff price followed by an increasing commercialization of smallholder farmers represents an opportunity to directly increase the living standard of rural communities in Ethiopia [20]. Despite its economic importance in Ethiopia, the productivity of teff remains low. For instance, in 2018/19 production year, teff yield was $17.56 \mathrm{qt} / \mathrm{ha}$, significantly lower than other cereals, such as maize (39.92 qt/ha), sorghum (27.36 qt/ha) and wheat (27.64 qt/ha) [11]. The low teff yield is apparently explained by the limited knowledge about the possible avenues for improving teff productivity, together with the problems inherent to its botany. Moreover, teff yield is low because of lodging, low modern input use, traditional way of sowing, socio-economic factors such as lack of access to market information, post-harvest losses and lack of high yielding cultivars $[6,33]$.

Consequently, in Ethiopia, to increase the productivity of teff several improved varieties were developed and disseminated to farmers along with their optimum management practices [29]. However, different area-specific evidences indicate that intensity and adoption rate of improved teff varieties in the country is low. This low rate of adoption decisions of farmers is usually determined by various factors which can be specific to socio-economic, institutional, demographic and psychological. In addition, factors such as expensiveness and unavailability of seeds and desired varieties, lack of awareness and the serious sequence of agronomic practices have commonly been mentioned as the constraints contributing to the low level of improved teff varieties adoption $[35,17,3]$.

The study area is mainly characterized by erratic rainfall condition, dependence on traditional technology and risk prone farming systems. As a result, crop production has become highly unpredictable and subsistence throwing the major proportion of the rural population in to food insecurity situation [28]. Apparently, food security of the majority of farmers can be enhanced through improving the performance agricultural production in the area. As part of this goal, in the study area improved teff varieties are often introduced in a package program although adopters use part of the package.

In spite of such intervention, information with regard to adoption of improved teff varieties on location specific factors influencing adoption and intensity of adoption of improved teff varieties being promoted in the districts was not empirically studied and documented. Hence, this study was aimed at analyzing factors affecting the adoption and intensity of use of improved teff varieties in order to draw important conclusions and policy implications for future intervention.

\section{Methodology}

\subsection{Description of the Study Area}

The study was conducted at Kobo district, Northeastern escarpment of Amhara Region. The district town, Kobo is located on the Addis Ababa-Adigrat highway, found around 575 kilometers away from Addis Ababa. The landscape of this district is characterized by a broad fertile plain which is separated from the lowlands of the Afar Region by the Zobil Mountains, which are over $2000 \mathrm{~m}$. a. s. 1. [26]. The mean annual rainfall ranges between $500-800 \mathrm{~mm}$ while the temperature varies from a minimum of $19^{\circ} \mathrm{C}$ to a maximum of $33^{\circ} \mathrm{C}$ annually [28]. The agro- climatic feature of the area is tropical as $7.9 \%, 37.2 \%$ and $54.9 \%$ are Dega, Weyina dega and Kola respectively. In the district, there are 34 rural and 6 urban Kebele administrations. The total population in the district was estimated to be 239,504 , of whom 120,383 were males and 119,121 were females [10].

The agricultural practice in Kobo is mainly characterized by mixed farming system where nearly $66.5 \%$ of the population is engaged in mixed farming whereas $27 \%$ and $2 \%$ of the population depend only on crop and livestock production respectively [26]. Crop production sub system in the district is both rain fed and irrigated. The rain fed crop production is dominated by cereals such as sorghum and teff whereas the irrigation crop farming is dominated by vegetables and cereals again. Improved teff varieties cultivated in the district are Quncho, Boset and Zobel. Currently, Quncho and Boset are widely cultivated varieties by farmers.

\subsection{Data Type, Sources and Methods of Data Collection}

The study used data generated from both primary and secondary sources. Cross sectional data of 2015/16 production season was used. This contains both quantitative and qualitative data collected from selected households with semi-structured questionnaire. Interview schedule was mainly used as a data collection tool. The interview schedules were first pre-tested using non-sample respondents before actual data collection and amendments were made. Accordingly, primary data were collected by interviewing smallholder farmers growing teff during the 2015/16 production season. This contains data on key demographic, institutional and socio-economic factors affecting adoption decision and intensity of adoption of improved teff varieties 
and the perceptions towards improved teff attributes were collected. While, secondary data were collected from books, journals and other published and unpublished documents, from district agricultural offices, websites and other related sources to supplement primary data.

\subsection{Sampling Procedure and Sample Size}

Multi-stage sampling procedure was employed to select representative sample households. In the first stage, Kobo District from North Wollo Zone was selected purposively based on maximum cultivated land under teff. In the second stage, 4 Kebeles were selected randomly from 20 teff producing Kebeles of the district. Then, the farmers in each randomly selected Kebeles were stratified into adopter and non-adopter categories giving the relative homogeneity of sample respondents' adoption status. Finally, from each stratum of the randomly selected Kebeles, 150 representative sample respondents were selected randomly through taking probability proportional to size of teff growing households in each kebeles for both groups.

\subsection{Methods of Data Analysis}

The study used both descriptive statistics and econometric model for analyzing the data. Descriptive statistics such as mean, standard deviation, frequencies distribution and percentage were employed in order to have clear picture about the socio-economic, institutional and demographic characteristics of sample households. Chi-square test and independent sample t-test were used to see the presence of systematic association between those who adopt and those who do not in terms of hypothesized variables.

Econometric Analysis: Various researchers used different models for analyzing the determinants of technology adoption. In principle, the decisions on whether to adopt and how much to adopt can be made jointly or separately [7]. Several adoption studies have used Tobit model to estimate adoption relationships with limited dependent variables. Tobit model is, however, statistically restrictive because it assumes that the same set of variables determine both the probability of adoption and intensity level. In this case, the appropriate approach is to use double-hurdle model. This model assumes farmers faced with two hurdles in any agricultural decision making processes [12]. In this study, double-hurdle model was used since it allows for the distinction between the determinants of improved teff variety adoption and the intensity of use of improved teff varieties through two separate stages. The model estimation involves running a probit regression to identify factors affecting the decision to adopt using all sample households in the first stage and a truncated regression model on the participating households to analyze the intensity of adoption in the second stage.

As already noted, the general form of Cragg's doublehurdle model (probit and truncated models in particular) that was used for this study is specified as follows.

$$
D^{*}{ }_{i}=W_{i}^{\prime} \alpha+U_{i} \text { (Adoption Decision Equation) }
$$

$$
D_{i}=1 \text {, if } D_{i}^{*}>0, D_{i}=0 \text {, otherwise }
$$

Where, $D *$ is the latent variable describing the household's decision of whether or not to adopt improved teff varieties that takes the value 1 if the household adopted and 0 otherwise, $D_{i}$ is the observed variable which represents the household's adoption decision, $\mathrm{W}_{\mathrm{i}}$ is a vector of explanatory variables, $\alpha$ is a vector of parameters to be estimated and $U_{i}$ is the error term.

$$
Y^{*}{ }_{i}=X_{i}^{\prime} \beta+V_{i}(\text { Intensity Equation })
$$

$$
Y_{i}=Y_{i}^{*}=X_{i} \beta+V_{i} \text { if } Y_{i}^{*}>0 \text { and } D^{*}{ }_{i}>0 \mathrm{Y}_{i}=0 \text {, otherwise }
$$

Where, $\mathrm{Y}_{\mathrm{i}}^{*}$ is the latent variable describing the intensity of adoption of improved teff varieties. $\mathrm{Y}_{\mathrm{i}}$ is the area of improved teff varieties cultivated in hectare signifying the intensity of adoption. $X_{i}$ is vector of explanatory variables influencing how much the household use improved teff varieties, $\beta$ is a vector of parameters to be estimated and $V_{i}$ is the error term. If both decisions are made by the individual farmers independently, the error term are assumed to be independently and normal distributed as: $\mathrm{U}_{\mathrm{i}} \sim \mathrm{N}(0,1)$ and $\mathrm{V}_{\mathrm{i}} \sim \mathrm{N}\left(0, \delta^{2}\right)$

The log-likelihood from the Cragg type double-hurdle model is the sum of the log-likelihood from a probit and a truncated regression. Hence, double-hurdle model is given by:

$$
\log 1=\sum_{0} \ln \left(1-\Phi\left(W_{i}^{\prime} \alpha\left(\frac{\mathrm{X}_{i} \boldsymbol{\beta}}{\sigma}\right)\right)\right)+\sum_{+} \ln \left(\Phi\left(W_{i}^{\prime} \boldsymbol{\alpha}\right) \frac{1}{\sigma} \varphi\left(\frac{\mathrm{Y}_{i}-\mathrm{X}_{i} \boldsymbol{\beta}}{\sigma}\right)\right)
$$

Where, $\Phi$ and $\phi$ are standard normal cumulative distribution function and density function respectively.

To determine the appropriateness of models, a hypothesis test for the double-hurdle model against the Tobit model was made. The test can be done by separately estimating Tobit, truncated and probit regression models and then conducting a likelihood ratio test that compares the Tobit with the sum of the log-likelihood functions of the probit and truncated regression models. The LR statistic can be computed using the formula developed by [16] as:

$$
\Gamma=-2\left[\ln L_{T}-\left(\ln L_{P}+\ln L_{T R}\right)\right] \sim \chi_{k}^{2}
$$

Where, $\mathrm{L}_{\mathrm{T}}=$ likelihood for the Tobit model; $\mathrm{L}_{\mathrm{P}}=$ likelihood for the probit model; $\mathrm{L}_{\mathrm{TR}}=$ likelihood for the truncated regression model and $\mathrm{k}$ is the number of independent variables in the equations.

The test hypothesis is written as: $\mathrm{H}_{0}: \lambda=\frac{\beta}{\sigma}$ and $\mathrm{H}_{1}: \lambda \neq \frac{\beta}{\sigma}$

The null hypothesis ( $\mathrm{H} 0)$ that Tobit model is the best fit model will be rejected on a pre-specified significance level if $\Gamma>\chi_{k}^{2}$.

\section{Result and Discussions}

\subsection{Rate and Intensity of Improved Teff Varieties Adoption by Sample Households}

In the study area, farmers are commonly cultivating three improved varieties namely, Quncho, Boset and Zobel. Table 1 
summarizes adoption status and area covered by improved teff varieties of adopter sample households. The results indicated that, out of the total adopters, $27(37.5 \%)$ of them were practice Quncho, $33(45.8 \%)$ were used Boset and it was most widely adopted variety, and only $12(16.7 \%)$ of the adopters were users of Zobel teff variety. In this study, the adoption intensity measures the extent of adoption expressed in terms of area of land allocated to improved teff varieties. An average of 0.35 ha of land was found to be allocated for improved teff varieties by adopter sample households. Out of which, on average $0.11,0.17$ and 0.07 ha of land was allocated to Quncho, Boset and Zobel respectively.

Table 1. Adoption status and area covered by improved teff varieties.

\begin{tabular}{llll}
\hline \multirow{2}{*}{ Variety } & \multicolumn{2}{l}{ Growers } & $\begin{array}{l}\text { Average area } \\
\text { (ha) }\end{array}$ \\
\cline { 2 - 3 } & $\mathbf{N}$ & $\mathbf{\%}$ & 0.11 \\
Quncho & 27 & 37.5 & 0.17 \\
Boset & 33 & 45.8 & 0.07 \\
Zobel & 12 & 16.7 & 0.35 \\
All improved varieties & 72 & 100 & \\
\hline
\end{tabular}

Source: own survey results, 2016

\subsection{Result of Descriptive Statistics for Dummy and Continuous Explanatory Variables}

The descriptive statistics of socio-economic, demographic and institutional characteristics of sample respondents examined in this study are presented in Tables 2 and 3. Table 2 presents for dummy variables whereas Table 3 presents for continuous variables. Out of the total sample respondents 72 (48\%) were adopters and $78(52 \%)$ were non-adopters.

Table 2 shows the result of descriptive statistics for dummy explanatory variables. Totally, 150 household heads were considered in this study. Out of these, $134(89.3 \%)$ were male headed and the remaining $16(10.7 \%)$ were female headed households. The chi-square test was computed for dummy variables and it was found to be statistically significant for credit access at 5\% significance level, for perception of farmers towards yield, participation on demonstration, improved teff seed availability and education level at $1 \%$ significance level and for membership to an organization it was found to be statistically significant at $10 \%$ significance level.

Table 3 shows the result of descriptive statistics for continuous variables. As indicated from the table, t-value was computed for all continuous variables and it was found to be statistically significant for family labor in adult equivalent, livestock holding in TLU, distance from the nearest market, cultivated land size and proportion of cultivated land allocated for teff at $1 \%$ level of significance and for age of the household head at $10 \%$ level of significance. This implies that there was significant difference in all these variables between the two adoption categories.

Table 2. Descriptive statistics for dummy explanatory variables.

\begin{tabular}{|c|c|c|c|c|c|c|c|c|}
\hline \multirow{2}{*}{ Variables } & & \multicolumn{2}{|c|}{ Adopters } & \multicolumn{2}{|c|}{ Non-adopters } & \multicolumn{2}{|c|}{ Total } & \multirow{2}{*}{$\chi^{2}$-value } \\
\hline & & $\mathbf{N}$ & $\%$ & $\mathbf{N}$ & $\%$ & $\mathbf{N}$ & $\%$ & \\
\hline \multirow{2}{*}{ Sex of household head } & Male & 67 & 93.1 & 67 & 85.9 & 134 & 89.3 & \multirow[t]{2}{*}{2.01} \\
\hline & Female & 5 & 6.9 & 11 & 14.1 & 16 & 10.7 & \\
\hline \multirow[t]{4}{*}{ Education level } & Illiterate & 12 & 16.7 & 45 & 57.7 & 57 & 38 & \multirow[t]{4}{*}{$42.25^{* * *}$} \\
\hline & Read \& write & 23 & 31.9 & 27 & 34.6 & 50 & 33.3 & \\
\hline & Grade (1-8) & 30 & 41.7 & 6 & 7.7 & 36 & 24 & \\
\hline & Grade $9 \&$ above & 7 & 9.7 & 0 & 0 & 7 & 4.7 & \\
\hline \multirow{6}{*}{$\begin{array}{l}\text { Participation on } \\
\text { demonstration } \\
\text { Improved teff seed } \\
\text { availability } \\
\text { Access to credit }\end{array}$} & Yes & 61 & 84.7 & 31 & 39.7 & 92 & 61.3 & \multirow[t]{2}{*}{$31.94^{* * *}$} \\
\hline & No & 11 & 15.3 & 47 & 60.3 & 58 & 38.7 & \\
\hline & Yes & 71 & 98.6 & 57 & 73.1 & 128 & 85.3 & \multirow[t]{2}{*}{$19.50^{* * *}$} \\
\hline & No & 1 & 1.4 & 21 & 26.9 & 22 & 14.7 & \\
\hline & Yes & 39 & 54.2 & 27 & 34.6 & 66 & 44 & \multirow[t]{2}{*}{$5.81^{* *}$} \\
\hline & No & 33 & 45.8 & 51 & 65.4 & 84 & 56 & \\
\hline \multirow{2}{*}{$\begin{array}{l}\text { Membership to an } \\
\text { organization }\end{array}$} & Yes & 61 & 84.7 & 57 & 73.1 & 118 & 78.7 & \multirow[t]{2}{*}{$3.03^{*}$} \\
\hline & No & 11 & 15.3 & 21 & 26.9 & 32 & 21.3 & \\
\hline \multirow{2}{*}{ Perception on yield capacity } & Yes & 62 & 86.1 & 38 & 48.7 & 100 & 66.7 & \multirow[t]{2}{*}{$23.56^{* * *}$} \\
\hline & No & 10 & 13.9 & 40 & 51.3 & 50 & 33.3 & \\
\hline
\end{tabular}

Table 3. Descriptive statistics for continuous explanatory variables.

\begin{tabular}{|c|c|c|c|c|c|c|c|}
\hline \multirow{2}{*}{ Variables } & \multicolumn{2}{|c|}{ Adopters } & \multicolumn{2}{|c|}{ Non-adopters } & \multicolumn{2}{|c|}{ Combined } & \multirow{2}{*}{ t-value } \\
\hline & Mean & Std. Dev. & Mean & Std. Dev. & Mean S & ev. & \\
\hline Age of household head & 41.93 & 8.90 & 44.78 & 9.80 & 43.41 & 9.43 & $-1.86^{*}$ \\
\hline Farming experience & 20.00 & 8.40 & 18.18 & 9.46 & 19.05 & 8.98 & 1.24 \\
\hline Family labor & 2.75 & 0.96 & 2.07 & 0.84 & 2.39 & 0.95 & $4.61^{* * *}$ \\
\hline Off/non-farm income & 5574.2 & 9895.2 & 3592.2 & 9016.1 & 4543.6 & 9468.6 & 1.28 \\
\hline Cultivated land size & 0.99 & 0.36 & 0.81 & 0.29 & 0.89 & 0.34 & $3.59^{* * *}$ \\
\hline Livestock holding & 3.43 & 1.61 & 2.11 & 1.40 & 2.74 & 1.64 & $5.34^{* * *}$ \\
\hline Distance from the nearest market & 9.39 & 1.80 & 11.05 & 1.62 & 10.26 & 1.89 & $-5.89^{* * *}$ \\
\hline Proportion of cultivated land allocated for teff & 0.42 & 0.19 & 0.34 & 0.13 & 0.38 & 0.16 & $3.05^{* * *}$ \\
\hline
\end{tabular}

***and *represents the level of significance at $1 \%$ and $10 \%$ respectively.

Source: own survey results, 2016 


\subsection{Econometric Model Results}

Prior to the estimation of the Double-hurdle model the variables included in the models were tested for multicollinearity using correlation coefficient. The test result shows that the problem of multi-collinearity among all the explanatory variables did not find. A hypothesis test of Double-hurdle model against Tobit model was made. Accordingly Double-hurdle model was chosen over Tobit model and used to analyze the influence of various demographic, socio-economic and institutional variables on adoption and intensity of use of improved teff varieties. This is done based on log-likelihood ratio test. The test statistics of the double-hurdle versus the Tobit model indicated the rejection of Tobit model and acceptance of the double-hurdle model. The test result in Table A1 revealed that the calculated statistical value of likelihood ratio was 90.64 which was greater than the tabulated or critical value of $\chi^{2}$ $(16)=32$ at $1 \%$ level of significance. This result provides an empirical result of farmers' independent decisions making regarding the adoption and intensity of use of improved teff varieties in the study area.

\subsubsection{Factors Determining the Probability of Adopting Improved Teff Varieties}

The results of the probit (first hurdle) model of the doublehurdle revealed that out of sixteen variables included in the model nine were found to be significantly influencing farmers' decision to adopt improved teff varieties. Detail of significant variables from the probit model are discussed as follows.

Education level of household head had a significant positive influence on the probability of adoption of improved teff varieties at $1 \%$ level of significance. This might be due to relatively literate farmers having more access to information, capable to interpret and analyze the information and become aware to new technology than illiterate farmers and this awareness enhances the adoption of new technologies. The model result indicates that, as compared to illiterate farmers the probability of adoption of improved teff varieties for literate farmers would increase by $35.3 \%$. Similarly [23, 5 , 24] reported that having education increases the probability of adoption of new agricultural technology by farmers.

As the model result indicates, the variable off/non-farm income was positively and significantly influenced the likelihood of adoption of improved teff varieties at 5\% significance level. Keeping all other variables constant, for each additional $1 \%$ increase in off/non-farm income the probability of adopting improved teff varieties increases by $4 \%$. Hence, the result of this study revealed that farmers with relatively higher off/non-farm income are more likely to use improved teff varieties as compared to farmers with lower income. The reason might be off/non-farm income increases the income of the household and might increase the capacity to invest in technology adoption. The result is consistent with other findings by $[18,9]$.

Proportion of cultivated land allocated for teff had a positive and significant effect on the probability of adoption of improved teff varieties at 5\% level of significance. Other variables held constant, the mariginal effect showed that an increase in proportion of cultivated land allocated for teff by $1 \%$ would result in $148.8 \%$ increase on the probability of adoption of improved teff varieties. This result implied that farmers who allocate relatively higher proportion of land for teff are more likely to adopt improved teff varieties than farmers who allocate relatively smaller proportion of land for teff production. The reason might be an increased risk taking behavior of farmers' with an increase proportion of teff area. Consistent with this, $[40,30]$ found that the higher the share of crop area the more likely to increase the use of improved technologies.

The number of tropical livestock unit had affected positively and significantly the probability of adoption of improved teff varieties at $5 \%$ probability level. Other variables held constant, as the number of livestock increase by one TLU, the probability of adoption of improved teff varieties increases by $13.4 \%$. The result could be explained as, better risk bearing behavior of those wealthy farmers with better livestock would enable them to try those newly adopted teff varieties. Previous empirical findings by $[27,13]$ confirms this result.

As hypothesized, frequency of farmers extension contact with agricultural extension agents had a positive and significant effect on the probability of adoption of improved teff varieties at 5\% level of significance. Other variables held constant, for each additional contact with extension agents the probability of adoption of improved teff varieties increases by $2.8 \%$. The result indicated higher probability of farmers with more contact with extension agents in adopting than farmers with less contact. The possible justification for this is that frequent contacts create awareness and build the necessary knowledge for using the innovation and enhancing the exposure of farmers on the adoption practice of improved technologies. The result is similar with the finding of [39, 21].

Households' participation on crop production demonstration positively and significantly influenced the probability of adoption of improved teff varieties at 5\% significant level. Other variables held constant, participation on demonstration would result in $36.7 \%$ increase on the probability of adoption of improved teff varieties. The result in relation to this variable showed that farmers who have opportunity to attend demonstration of improved teff technology are more likely to use improved teff varieties than those farmers who have no similar opportunity. The reason might be participation on demonstration help farmers to create awareness and promote the understanding about merits of the available information by showing the practical applicability of the technology selected to be adopted. This result goes along with previous studies by [1,22].

Availability of improved teff seed was found to be positively and significantly influenced the probability of adoption of improved teff varieties at 5\% probability level. 
Other variables held constant, timely availability of improved teff seed brings about $52.5 \%$ increase in the probability of adoption of improved teff varieties. The result implied that those farmers who get improved seed are more likely to adopt improved teff variety than those who do not have access. The possible explanation for this finding could be timely availability of seeds either in the local stores or in the market eases the households to purchase and cultivate new improved varieties in their fields. The result is consistent with studies by $[15,36]$ who found that availability improved seeds affect probability of adopting improved varieties.

Distance from the nearest market had a negative and significant influence on the probability of adoption of improved teff varieties at $1 \%$ level of significance. Keeping other variables constant, an increase in distance from farmers' residence to market place by a kilometer would result in $14.6 \%$ reduction on the likelihood of adoption of improved teff varieties. The result implied that the longer the distance between farmers' residence and the market place, the lower will be the probability of adoption of improved teff varieties. The plausible explanation for this result might be farmers nearby the market centers had more access to production inputs, have higher probability of obtaining up-todate market information and hence access more information about improved technology that could enable them to try new technologies than those farmers who are in distant location. The finding of this research is in line with $[19,13]$.

Farmers' perception of better yielding character of improved teff varieties was significantly and positively affected the adoption decision of the farm households at 5\% level of significance. Other variables held constant, a change in the perception of the farmer on the yield of improved variety to be higher than that of local variety (that is, a change from 0 to 1 ) brings $33.8 \%$ increase in the probability of adoption. The result of this study showed that if farmers perceive that new varieties are superior in terms of yield as compared to the local varieties, they will more likely adopt and widely use them. The possible reason is that farmers' interest of maintaining and enhancing teff yield in the production year. The result is similar with the finding of $[14,5]$.

\subsubsection{Factors Determining the Intensity of Adopting Improved Teff Varieties}

The factors affecting the intensity of use of improved teff varieties were estimated using truncated regression model. The model result from Table 4 indicated that from sixteen variables included in the model seven were found to be significantly affecting the intensity of use of improved teff varieties at different probability levels. Detail of significant variables from this model are discussed as follows.

Sex of household heads had positive and significant effect on the intensity of use of improved teff varieties at 5\% level of probability. As compared to female headed households, the intensity of use of improved teff varieties for male headed household increased by $14.7 \%$. The result suggests that those male headed households are more likely to allocate larger amount of land to improved teff varieties than their counter parts, ceteris paribus. This could be attributed to various reasons, which could be the problem of economic position of female headed households, including shortage of labor, limited access to information on improved varieties and required production inputs due to social position. The result is consistent with the findings of $[23,19,5]$.

Age had negative and significant influence on the intensity of use of improved teff varieties at 5\% probability level. Other variables held constant, as age of the household increases by a year, the intensity of use of improved teff varieties decreases by $0.5 \%$. The result implied that older household heads are resistent and less likely to adopt improved varieties than young household heads. The possible justification is that as the household heads get old they might reduce trust towards new technologies adoption as new technologies need financial investments and intensive field managements. The result in accordance with the findings of [34, 4].

Family labor in adult equivalent was positively and significantly influenced the intensity of using improved teff varieties at $10 \%$ probability level. Keeping all other variables constant, a unit increase in family labor, increases the intensity of use of improved teff varieties by $2.6 \%$. This result indicated that farmers with high labor force are more likely to allocate more hectares of land to improved teff varieties than those with low labor force. The possible reason is that teff production is a labor-intensive activity and hence a household with high working labor force would be in a position to manage the labor-intensive teff production activity. Previous studies by $[31,19,24]$ also reported that the more family labour available the better intensity of adoption of agricultural technologies.

Off/non-farm income positively and significantly influenced the intensity of using improved teff varieties at $1 \%$ level of significance. Other variables held constant, $1 \%$ increase in off/non-farm income increases the intensity of use of improved teff varieties by $0.9 \%$. This result showed that households with relatively higher off/non-farm income are expected to allocate more hectares of land to improved teff varieties than their counterparts. The probable reason for this finding is that additional income earned through participation in off/non-farm activities improves farmers' financial capacity and might increase the ability to acquire improved seeds and associated inputs. This result goes along with the previous studies by $[8,27,9]$.

The proportion of cultivated land allocated for teff was found to have positive and significant influence on the intensity of using improved teff varieties at 5\% level of significance. Other variables held constant, each $1 \%$ increase in proportion of cultivated land allocated for teff production would result in $23.4 \%$ increase in the intensity of use of the improved teff varieties. As stated by [39, 30], farmers who allocate higher proportion of cultivated land for their crops are more likely to use improved technologies extensively than those farmers with smaller proportion of cultivated land.

As expected, frequency of extension contact was found to be positively and significantly influenced the intensity of adoption of improved teff varieties at $10 \%$ probability level. 
The intensity of adopting improved teff varieties increases by $0.45 \%$ as for each additional contact with extension agents. The result implied that frequent contact with extension agents increases the availability of information about improved technologies and make farmers being aware of new technologies on how they can apply and hence increase the intensity of use of technologies. The result is consistent with the findings of $[18,21,24]$.

Intensity of use of improved teff varieties was positively and significantly influenced by membership of organizations at $1 \%$ level of significance. The model result indicates that as compared to non-membership to organizations, being membership in organizations would increase in the intensity of use of improved teff varieties by $10.6 \%$. Farmers' organization could served as aplatform for accessing and dissemination of new information and improved technologies. Hence, the result of the study implied that farmers belonging to organizations have easy access to information, credit, labor and inputs such as, fertilizer, improved seeds and chemicals and are expected to allocate more hectares of land to improved vareities. The result is consistent with other previous studies by [4].

Table 4. Parameter estimates of Cragg's double-hurdle model for adoption and intensity of adoption of improved teff varieties.

\begin{tabular}{|c|c|c|c|c|c|}
\hline \multirow{2}{*}{ Variables } & \multicolumn{3}{|c|}{ Adoption decision (probit model) } & \multicolumn{2}{|c|}{ Intensity of adoption (truncated model) } \\
\hline & Coef. & Std. Err & Marginal effect & Coef. & Std. Err \\
\hline Sex of the household head & -0.1249 & 0.6666 & -0.0498 & $0.1468 * * *$ & 0.0543 \\
\hline Age of the household head & 0.0072 & 0.0281 & 0.0029 & $-0.0049 * *$ & 0.0021 \\
\hline Educational level & $0.8851 * * *$ & 0.2481 & 0.3527 & -0.0100 & 0.0145 \\
\hline Family labor & 0.1336 & 0.2247 & 0.0532 & $0.0263 *$ & 0.0139 \\
\hline Off/non-farm income & $0.1005 * *$ & 0.0422 & 0.0400 & $0.0090 * * *$ & 0.0028 \\
\hline Farming experience & 0.0082 & 0.0278 & 0.0032 & -0.0028 & 0.0020 \\
\hline Proportion of teff cultivated land & $3.7331 * *$ & 1.8491 & 1.4875 & $0.2335 * *$ & 0.1026 \\
\hline Livestock holding & $0.3352 * *$ & 0.1606 & 0.1335 & 0.0041 & 0.0087 \\
\hline Frequency of extension contact & $0.0705 * *$ & 0.0349 & 0.0280 & $0.0045^{*}$ & 0.0025 \\
\hline Participation on demonstration & $0.9678 * *$ & 0.4505 & 0.3673 & 0.0389 & 0.0411 \\
\hline Improved teff seed availability & $1.7774 * *$ & 0.8102 & 0.5254 & -0.0576 & 0.1060 \\
\hline Distance from the nearest market & $-0.3674 * * *$ & 0.1103 & -0.1464 & 0.0023 & 0.0070 \\
\hline Access to credit & 0.4732 & 0.3697 & 0.1869 & 0.0278 & 0.0248 \\
\hline Perception on yield capacity & $0.8915 * *$ & 0.4441 & 0.3380 & 0.0057 & 0.0380 \\
\hline _CONS & $-4.6099 * * *$ & 1.7801 & - & 0.1932 & 0.1534 \\
\hline$\overline{\mathrm{LR}} /$ Wald $\mathrm{chi}^{2}(16)$ & 131.22 & & & 78.24 & \\
\hline Prob $>$ chi $^{2}$ & 0.000 & & & 0.000 & \\
\hline Log likelihood & -38.24 & & & 70.39 & \\
\hline Pseudo $\mathrm{R}^{2}$ & 0.63 & & & - & \\
\hline Number of observations & 150 & & & 72 & \\
\hline
\end{tabular}

$* * *, * *$ and $*$ represents the level of significance at $1 \%, 5 \%$ and $10 \%$ respectively. Source: Model output

\section{Conclusions}

The study was initiated to identify factors affecting the probability of adoption and intensity of use of improved teff varieties in kobo district. A double-hurdle econometric model was employed. The study empirically provides that farmers' decision to adopt and the decision concerning intensity of use of improved teff varieties were made separately. The model result shows that level of education, off/non-farm income, and proportion of cultivated land allocated for teff production, frequency of extension contact, livestock holding, participation on demonstration, improved teff seed availability, and perception on yield were found positive and significant in the first hurdle while distance from the nearest market had negative and significant effect. Whereas, in the second hurdle, sex of household head, age of household head, off/non-farm income, family labor, proportion of cultivated land allocated for teff, frequency of extension contact and membership to an organization were found to be significantly influenced households' intensity of use of improved teff varieties. Clearly, the use of improved agricultural technologies particularly improved varieties is considered to be the most important input for the achievement of increased agricultural production and productivity of smallholder farmers in Ethiopia. However, in the study area the performance of farmers in terms of use of improved teff varieties has not been to the expected levels and the rate of adoption remains low. Hence, concerted efforts should be made to promote the use of improved agricultural technologies in teff farming. Moreover, understanding the factors that hinder adoption of improved teff varieties is vital in planning and executing technology related programmes for addressing the challenges of production enhancing technology adopted by farmers in Ethiopia particularly in the study area.

\section{Recommendations}

Based on the empirical findings of the study, the following recommendations are suggested. Since the level of education affected adoption of improved teff varieties, the diffusion of technology needed to be facilitated through educated farmers to be used as contact farmers so that they can use the available inputs more efficiently under the existing 
technology. In the study area, emphasis need to be given to increase adoption of improved teff varieties by making better access to improved seeds timely. Strengthening extension service is needed to increase farmers' awareness about the benefits of using improved teff technologies including improved teff varieties as it enhances their ability to acquire and use information required for production.

Improving the existing market center in the study area through construction of whether roads and providing good transport facilities for farmers need to be given more attention to enhance the adoption of improved teff varieties. In the study area farmers' organization also need to be strengthened to reinforce farmer-to-farmer knowledge sharing should go through workshops, trainings and pertinent demonstration activities to capacitate their human and financial resources by providing incentives so that they can be the center for agricultural technology transformation. Sex of the household head was positive and significant on the intensity of use of improved teff varieties suggesting that due attention should be provided for promoting and empowering females by addressing the resource and information constraints. Policies should consider availability of labour force before introducing labour intensive technologies.

\section{Appendix}

Table A1. Test statistics for comparison of double-hurdle with Tobit Model.

\begin{tabular}{llll}
\hline & \multirow{2}{*}{ Tobit } & \multicolumn{2}{c}{ Double hurdle } \\
\cline { 3 - 4 } & & Probit & Truncated \\
\hline Wald/LR $\chi^{2}$ & 143.61 & 131.22 & 78.24 \\
Prob $>\chi^{2}$ & 0.000 & 0.000 & 0.000 \\
LOG-L & -13.17 & -38.24 & 70.39 \\
Number of observations (N) & 150 & 150 & 72 \\
Log likelihood ratio statistics & $\begin{array}{l}\Gamma=90.64>\chi^{2}(16)=32 \text { at } 1 \% \text { level of } \\
\text { significance }\end{array}$ & \\
\hline
\end{tabular}

Source: Data result, 2016

\section{References}

[1] Alemitu Mulugeta. (2011). Factors affecting adoption of improved haricot bean varieties and associated agronomic practice in Dale Woreda, Ethiopia. MSc Thesis, Hawassa University, Hawassa, Ethiopia.

[2] ATA (Agricultural Transformation Agency). (2017). Transforming Agriculture in Ethiopia. Annual Agricultural Report 2017/18. Addis Ababa, Ethiopia.

[3] ATA (Agricultural Transformation Agency). (2012). Working Strategy for Strengthening Ethiopia's Teff Value Chain Vision, Systemic Challenges, and Prioritized Interventions. Addis Ababa, Ethiopia.

[4] Aman Tufa and Tewodros Tefera. (2016). Determinants of improved barley adoption intensity in Malga District of Sidama Zone, Ethiopia. International Journal of Agricultural Economics, 1 (3): 78-83.
[5] Bayissa Gedefa. (2014). A double-hurdle approach to modeling of improved teff technologies adoption and intensity use: The case of Diga district of East Wollega Zone, Ethiopia. Global Journal of Environmental Research, 8 (3): 41-49.

[6] Bekabil Fufa, Befekadu Behute, Simons, R. and Tareke Berhe. (2011). Strengthening Teff Value Chain in Ethiopia: Teff Diagnostic Report. ATA, Addis Ababa, Ethiopia.

[7] Berhanu Gebremedhin and Swinton, S. M. (2003). Investment in soil conservation in Northern Ethiopia: The role of land tenure security and public programme. Journal of Agricultural Economics, 29 (1): 69-84.

[8] Berihun Kassa, Bihon Kassa and Kibrom Aregawi. (2014). Adoption and impact of agricultural technologies on farm income: Evidence from Southern Tigray, Northern Ethiopia. International Journal of Food and Agricultural Economics, 2 (4): 91-106

[9] Brkalem Shewatatek. (2015). Econometrics model on determinants of adoption of improved soil and water conservation practices: The case of Boloso-Sore Woreda, Woliata Zone, Ethiopia. Scholarly Journal of Scientific Research and Essay, 4 (2): 35-42.

[10] CSA (Central Statistical Agency). (2012). Summary and Statistical Report of the Population and Housing Census. Addis Ababa, Ethiopia.

[11] CSA (Central Statistical Agency). (2019). Agricultural Sample Survey: Area and Production of Crops, Main Season. Addis Ababa, Ethiopia.

[12] Cragg, J. G. (1971). Some statistical models for limited dependent variables with application to the demand for durable goods. Journal of the Econometric Society, 39 (5): 829-844.

[13] Debelo Duressa. (2015). Analysis of factors influencing adoption of quncho teff: The Case of Wayu Tuqa District. International Journal of African and Asian Studies, 12: 20-28.

[14] Ermias Tesfaye. (2013). Adoption of improved sorghum varieties and farmers' varietal trait preference: The case of Kobo District, North Wolo Zone, Ethiopia. MSc Thesis, Haramaya University, Haramaya, Ethiopia.

[15] Ghimire, R., Wen-chi, H. and Shrestha, R. B. (2015). Factors affecting adoption of improved rice varieties among rural farm households in Nepal. Rice Science, 22 (1): 35-43.

[16] Greene, W. H. (2003). Econometric Analysis, $5^{\text {th }}$ Edition. Macmillan, New York, USA.

[17] Hailu Beyene. (2008). Adoption of improved teff and wheat production technologies in crop and livestock mixed systems in Northern and Western Shewa Zones of Ethiopia. Doctoral Dissertation, University of Pretoria, South Africa.

[18] Hassen Beshir, Bezabih Emana, Belay Kassa and Jema Haji. (2012). Determinants of chemical fertilizer technology adoption in North Eastern highlands of Ethiopia. Journal of Research in Economics and International Finance, 1 (2): 3949.

[19] Hassen Beshir. (2014). Factors affecting adoption and intensity of use of improved forages in North East Highlands of Ethiopia. American Journal of Experimental Agriculture, 4 (1): $12-27$. 
[20] Hauenstein, S. (2015). Assessing the resilience of teff value chain in Ethiopia. MSc Thesis, Swiss Federal Institute of Technology, Zurich, Swisserland.

[21] Idrisa, Y. L., Shehu, H. and Ngamdu, M. B. (2012). Effects of adoption of improved maize seed on household food security in Gwoza local government area of Borno State, Nigeria. Global Journal of Science Frontier Research, 12: 5-12.

[22] Kafle, B. (2011). Factors affecting adoption of organic vegetable farming in Chitwan District, Nepal. World Journal of Agricultural Sciences, 7 (5): 604-606

[23] Lavison, R. (2013). Factors influencing the adoption of organic fertilizers in vegetable production in Accra. MSc Thesis, Accra, Ghana.

[24] Leake Gebreselassie and Adam Bekele. (2015). Factors determining allocation of land for improved wheat variety by smallholder farmers of northern Ethiopia. Journal of Development and Agricultural Economics, 7 (3): 105-112.

[25] Minten, B., Seneshaw Tamru, Ermias Engida and Tadesse Kuma. (2013). Ethiopia's Value Chains on the Move: The Case of Teff. ESSP II Working Paper 52. International Food Policy Research Institute (IFPRI). Addis Ababa, Ethiopia.

[26] OKARD (Office of Kobo Agricultural and Rural Development). (2015). Socio-economic Profile Description of Kobo District of Amhara Region, Ethiopia.

[27] Regasa Dibaba, Afework Hagos, Chilot Yirga and Endeshaw Habte. (2018). Determinants of improved teff varieties adoption and its impact on productivity: The case of nontraditional teff growing areas of Western Ethiopia. Journal of Natural Sciences Research, 22 (8): 2224-3186.

[28] SARC (Sirinka Agricultural Research Center). (2015). Annual report,. Sirinka, Ethiopia.

[29] Setotaw Ferede. (2013). Technological Change and Economic Viability in Teff Production. pp. 255-273. In: Kebebew, A., Solomon, C. and Zerihun, T. (eds.), Proceeding of the $2^{\text {nd }}$ International Workshop, Achievements and Prospects of Teff Improvement, 7-9 November 2011. Debre Zeit, Ethiopia.

[30] Sibanda, M., Mushunje, A. and Mutengwa, C. S. (2016). Factors influencing the demand for improved maize open pollinated varieties (OPVs) by smallholder farmers in the Eastern Cape Province, South Africa. Journal of Cereals and Oilseeds, 7 (2): 14-26.
[31] Solomon Asfaw, Bekele Shiferaw, Simtowe, F. and Messia Hagos. (2011). Agricultural technology adoption, seed access constraints and commercialization. Evidence from chickpea technologies in Ethiopia. Journal of Development and Agricultural Economics, 3 (9): 436-447.

[32] Tadesse Adgo. (2008). Farmers evaluation and adoption of improved onion production package in Fogera district, Northern Ethiopia. MSc Thesis, Haramaya University, Haramaya, Ethiopia.

[33] Tareke Berhe, Zewdie Gebretsadik, Edwards, S. and Hailu Araya. (2011). Boosting Teff Productivity Using Improved Agronomic Practices and Appropriate Fertilizer. Pp. 133-140. In: Kebebew, A., Solomon, T. and Chanyalew, Z. (eds.), Proceedings of the $2^{\text {nd }}$ International Workshop in Achievements and Prospects of Teff Improvement, November 7-9, 2011, Debre Zeit, Ethiopia.

[34] Teklewold Hailemaiam, Legesse Dadi, Alemu Yami and Dana, N. (2006). Determinants of adoption of poultry technology: Livestock Research for Rural Development, 18 (3).

[35] Tesfaye Teklu, Fassil Kelemework, Abera Deresa, Elias Zerfu, Kiflu Bedane and Legesse Dadi. (2001). Teff Technology Transfer and Adoption. Pp. 255-264. In: Hailu Tefera, Getachew Belay and Sorrells, M. (eds.), Proceedings of the International Workshop on Teff Genetics and Improvement, 16-19 October 2000. Addis Ababa, Ethiopia.

[36] Verkaart, S., Bernard, G., Mausch, K. and Jeffrey, D. (2016). Welfare impact of improved chickpea adoption in Ethiopia. Food policy, 66 (2): 50-61

[37] Worku, I., Dereje, M., Berhane, G., Minten, B. and Taffesse, A. (2014). Teff and its Role in the Agricultural and Food Economy. Ethiopian Research Institute. (Unpublished).

[38] WB (World Bank). 2013. Ethiopia Rural Socioeconomic Report. Addis Ababa, Ethiopia.

[39] Yaregal Mulu. (2011). Adoption of improved varieties of maize: The case of Dilla zuria Woreda, SNNPR, Ethiopia. MSc Thesis, Haramaya University, Haramaya, Ethiopia.

[40] Yu, B. and Nin-Pratt, A. (2014). Fertilizer adoption in Ethiopia's cereal production. Journal of Development and Agricultural Economics, 6 (7): 318-337. 